\title{
NOTIFICATION OF SECURITY THREATS ON THE INTERNET PROXY SERVER IS A SERVER-BASED SHORT MESSAGE SERVICE (SMS)
}

\author{
Mario Agapito Arizald Gobel, Sumarsono, Yuliani Indrianingsih \\ Jurusan Teknik Informatika \\ Sekolah Tinggi Teknologi Adisutjipto Yogyakarta \\ informatika@stta.ac.id
}

\begin{abstract}
Defense system against interference when the activity is generally done manually by the administrator. This resulted in the integrity of the system depends on the availability and speed of the administrator in response to disturbance. In the current era of information technology, almost all information is important for an institution can be accessed by its users. Disclosure of such access raises new security issues in part of a computer network system that is very important to maintain the validity and integrity of data and ensure availability of services for its users.

In this issue then designed a system to detect any interference. The detection is based filtering on the port service, using the programming language Delphi 7. The data obtained from the filtered traffic data packets passing the proxy server. By building a system that can work automatically and in real time, then perform the detection of intruders or illegal activities which will then be reported to the administrator.

With this administrator can find out the use of illegal ports through port filter techniques on the traffic data service in and out in real time, from both internal and external networks. Administrators can do the monitoring without having to depend on availability. With such a system administrator can perform tasks more efficiently in maintaining the validity and integrity of data. Key words: security threats, Internet Proxy Server, SMS.
\end{abstract}

\section{ABSTRAK}

Sistem pertahanan terhadap aktivitas gangguan saat ini umumnya dilakukan secara manual oleh administrator. Hal ini mengakibatkan integritas sistem bergantung pada ketersediaan dan kecepatan administrator dalam merespon gangguan. Dalam era teknologi informasi saat ini, hampir seluruh informasi yang penting bagi suatu institusi dapat diakses oleh para penggunanya. Keterbukaan akses tersebut memunculkan berbagai masalah. Keamanan jaringan komputer sebagian dari sebuah sistem yang sangat penting untuk menjaga validitas dan integritas data serta menjamin ketersediaan layanan bagi penggunanya.

Dalam permasalahan ini maka dirancang sebuah sistem untuk mendeteksi setiap gangguan. Pendeteksian dilakukan berdasarkan filtering pada port service, dengan menggunakan bahasa pemrograman Delphi 7. Data yang terfilter didapat dari lalulintas paket data yang lewat di proxy server. Dengan membangun sebuah sistem yang dapat bekerja secara otomatis dan real time, lalu melakukan 
pendeteksian penyusup atau aktifitas-aktifitas terlarang yang kemudian akan dilaporkan kepada administrator.

Dengan ini administrator dapat mengetahui penggunaan port secara illegal melalui teknik filter port service pada lalulintas data yang keluar masuk secara real time, baik dari jaringan internal maupun eksternal. Administrator bisa melakukan pemantauan tanpa harus tergantung pada ketersediaan. Dengan sistem seperti ini administrator dapat dengan lebih efisien dalam melakukan tugas menjaga validitas dan integritas data.

\section{Kata kunci : Gangguan keamanan, Internet Proxy Server, SMS.}

\section{Latar Belakang}

Keamanan jaringan komputer sebagai bagian dari sebuah sistem yang sangat penting untuk menjaga validitas dan integritas data serta menjamin ketersediaan layanan bagi penggunanya. Sistem harus dilindungi dari segala macam serangan dan usaha-usaha penyusupan atau pemindaian oleh pihak yang tidak berhak. Sistem deteksi penyusup jaringan yang ada saat ini umumnya mampu mendeteksi berbagai jenis serangan tetapi tidak mampu mengambil tindak lanjut. Selain itu sistem juga tidak memiliki interaktivitas dengan administrator pada saat administrator tidak mengadministrasi sistemnya. Hal ini merupakan suatu kondisi yang tidak efektif terutama pada saat sistem berada dalam kondisi kritis.

Dalam era teknologi informasi saat ini, hampir seluruh informasi yang penting bagi suatu institusi dapat diakses oleh para penggunanya. Keterbukaan akses tersebut memunculkan berbagai masalah baru antara lain:

a. Pemeliharaan validitas dan integritas data/informasi.

b. Jaminan ketersediaan informasi bagi pengguna yang berhak.

c. Pencegahan akses informasi dari yang tidak berhak.

d. Pencegahan akses sistem dari yang tidak berhak.

Sistem pertahanan terhadap aktivitas gangguan saat ini umumnya dilakukan secara manual oleh administrator. Hal ini mengakibatkan integritas sistem bergantung pada ketersediaan dan kecepatan administrator dalam merespon gangguan. Apabila gangguan tersebut berhasil membuat suatu jaringan mengalami malfungsi, administrator mungkin saja tidak dapat lagi mengakses sistem secara remote sehingga ia tidak akan dapat melakukan pemulihan dengan cepat. Oleh karena itu di butuhkan suatu sistem yang dapat menanggulangi ancaman yang mungkin terjadi secara optimal dalam waktu yang cepat dan secara otomatis sehingga memungkinkan ketersediaan dan kecepatan administrator dalam merespon gangguan.

Dalam implementasinya untuk pengamana suatu sistem maka harus dilakukannya pendeteksian penyusup, deteksi penyusup sendri adalah aktivitas untuk mendeteksi penyusup melalui aktivitas yang dilakukan oleh penyusup dan secara cepat dengan menggunakan program khusus yang otomatis serta real time merespon gangguan atau aktivitas yang membahayakan tersebut. Dengan menggunakan metode seperti ini optimalisasi pengamanan suatu sistem dapat dilakukan dengan efisien oleh administrator.

\section{Landasan Teori \\ Proxy}


Proxy server adalah sebuah komputer yang memelihara dua hubunngan jaringan komputer antara internet dan jaringan local (internal). Proxy dapat dipahami sebagai pihak ketiga yang berdiri ditengah-tengah antara kedua pihak yang saling berhubungan dan berfungsi sebagai perantara, sedemikian sehingga pihak pertama dan pihak kedua tidak secara langsung berhubungan, akan tetapi masing-masing berhubungan dengan perantara, yaitu proxy. Tidak ada lalulintas jaringan yang lewat secara langsung tanpa melewati proxy server. Proxy server menyampaikan komunikasi dengan internet, kemudian mentransmisikan jawaban kembali ke pemakai internal asal.

Proxy dalam pengertiannya sebagai perantara, bekerja dalam berbagai jenis protokol komunikasi jaringan dan dapat berada pada level-level yang berbeda pada hirarki lapisan protokol komunikasi jaringan. Suatu perantara dapat saja bekerja pada lapisan Data-Link, layer Network dan Transport, maupun lapisan Aplikasi dalam hirarki layer komunikasi jaringan menurut OSI. Namun pengertian proxy server sebagian besar adalah untuk menunjuk suatu server yang bekerja sebagai proxy pada lapisan Aplikasi (Morgan Stern, 1998).

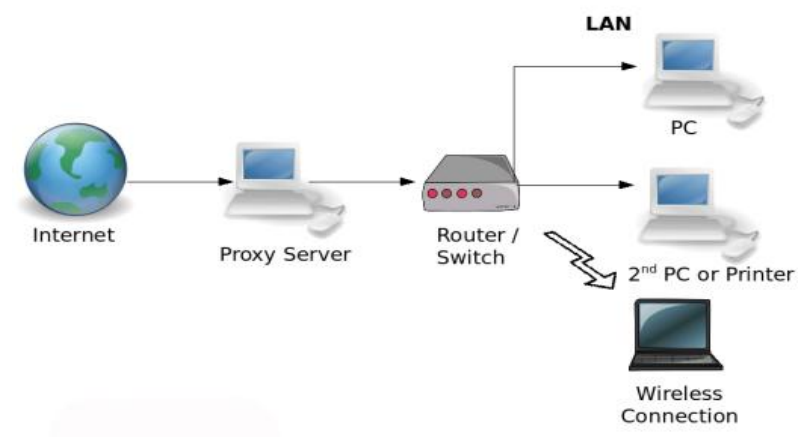

Gambar 1 Proxy Server.

\section{Notification}

Notification adalah pemberitahuan, dalam hal ini pemberitahuan yang dimaksud adalah pemberitahuan kepada Administrator. Notifikasi dalam hal ini berisi tentang informasi-informasi yang dibutuhkan oleh pengeloa jaringan untuk tujuan-tujuan tertentu misalnya dalam pengawasan jaringan. Informasi yang terdapat didalam Notifikasi terdiri dari beberapa bagian dari paket data yang keluar masuk di jaringan komputer melalui proxy. Informasi yang diberitahukan adalah sebagai berikut :

a. Time, waktu pada saat paket data dikirimkan.

b. IP Soure, nomor IP pengirim paket data.

c. Host Name, nama komputer pengirim paket data.

d. Service, port service yang digunakan (Telnet, SSH, HTTP, dll).

e. Port, nomor port yang digunakan.

Informasi ini dikirimkan sebagai notifikasi kepada pengelola yang menjadi bahan untuk pengawasan jaringan komputer atau tujuan lainnya.

\section{Socket}


Socket adalah salah satu titik akhir dari jalur komikasi dua arah antara dua program yang berjalan pada jaringan yang berjalan pada protokol TCP/IP atau UDP. Socket terhubung pada sebuah nomor port sehingga lapisan TCP dapat mengidentifikasi dimana pengrim data ditunjukan. Socket merupakan sebuah aplikasi yang dibuat, dikontrol antarmuka sistem operasi dimana aplikasi dapat saling mengirim dan menerima pesan dari atau pada aplikasi yang lain. Proses kerja socket dijelaskan pada gambar 2 .

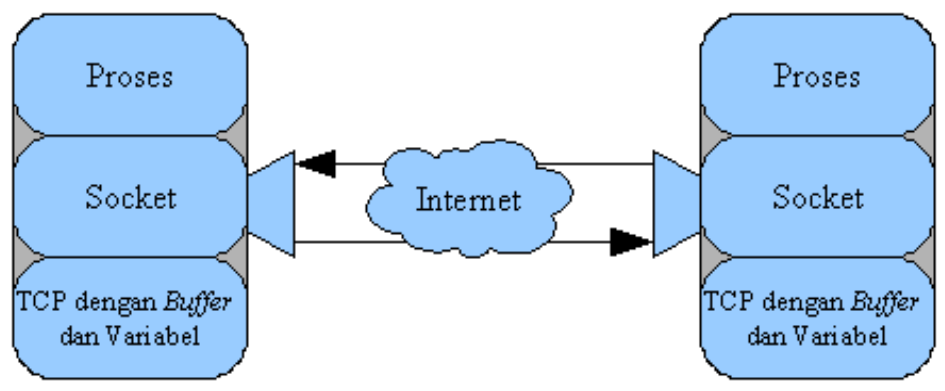

Gambar 2 Proses kerja socket.

Definisi tentang socket sebagai berikut:

a. Mengizinkan suatu proses unik untuk berkomunikasi satu dengan yang lain.

b. Memberitahukan proses mana untuk menulis atau membaca.

c. Komunikasi pada mesin yang sama, jaringan dan internet.

d. Komunikasi dua arah membuatnya cocok untuk model client server.

e. dibentuk tahun 1980 oleh Berkeley Unix Distribution.

Pada umumnya, sebuah server merupakan sebuah komputer yang khusus dan memiliki sebuah socket yang terhubung pada sebuah nomor port yang khusus. Server hanya menunggu socket untuk menerima permintaan koneksi (request) dari sebuah client (passive open). Client mengetahui nama mesin tempat server dijalankan dan nomor port server tersebut dihubungkan. Untuk membuat koneksi permintaan, client mencoba untuk melakukan koneksi dengan server pada mesin server dan port (active open), seperti yang dijelaskan pada gambar 3 .

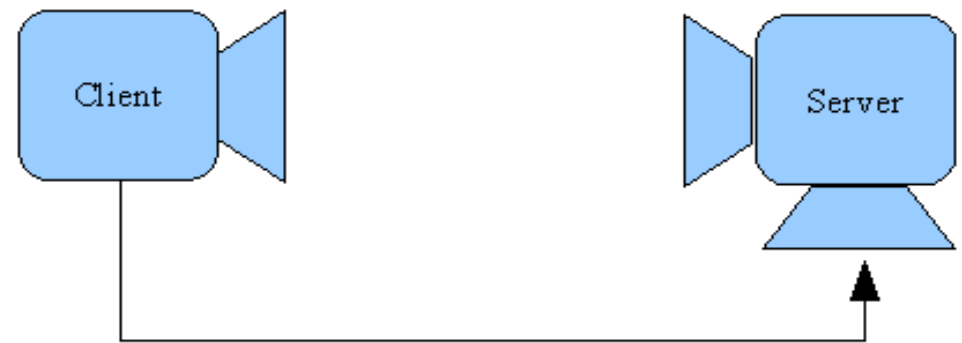

Gambar 3 Client meminta koneksi 
Apabila berjalan dengan baik maka server menerima koneksi (virtual circuit). Saat penerimaan, server membuka socket baru yang terhubung pada port yang berbeda. Untuk dapat melanjutkan penerimaan dari socket awal untuk koneksi permintaan saat melayani kebutuhan client yang terhubung, dibutuhkan sebuah socket baru (dengan nomor port yang beda), seperti yang dijelaskan pada gambar 4.

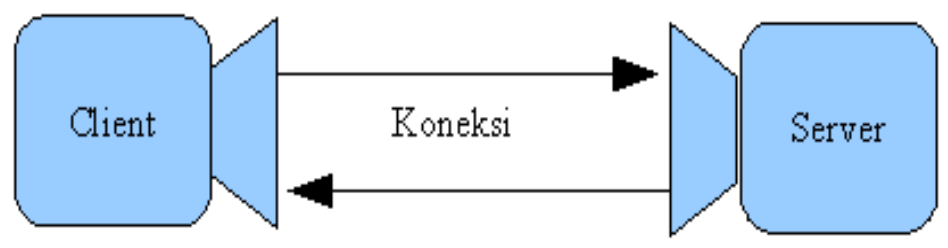

Gambar 4 Respon server

Pada sisi client, jika koneksi diterima, sebuah socket berhasil dibentuk dan client dapat menggunakan port tersebut untuk berkomunikasi dengan server. Client dan server sekarang dapat berkomunikasi untuk menulis dan membaca dari socket tersebut.

Ada 2 macam protokol yang dapat digunakan pada socket, yaitu:

a. TCP bersifat connection-oriented dan reliable.

1. Connection-oriented, untuk melakukan komunikasi diperlukan koneksi terlebih dahulu.

2. Reliable, menjamin sampainya paket data kekomputer tujuan dan melakukan pengecekan. Apabila ada paket data yang hilang atau rusak maka socket TCP akan meminta paket data yang rusak tersebut sampai semua paket data yang diterima dalam kondisi yang baik.

b. UDP bersifat connectionless dan unreliable.

Beberapa nomor port yang sering digunakan 21(FTP), 23(telnet), 25(SMTP), 69(TFTP), 80(HTTP). Ada beberapa langkah agar sebuah aplikasi client server dapat saling berkomunikasi, seperti pada Gambar 5.
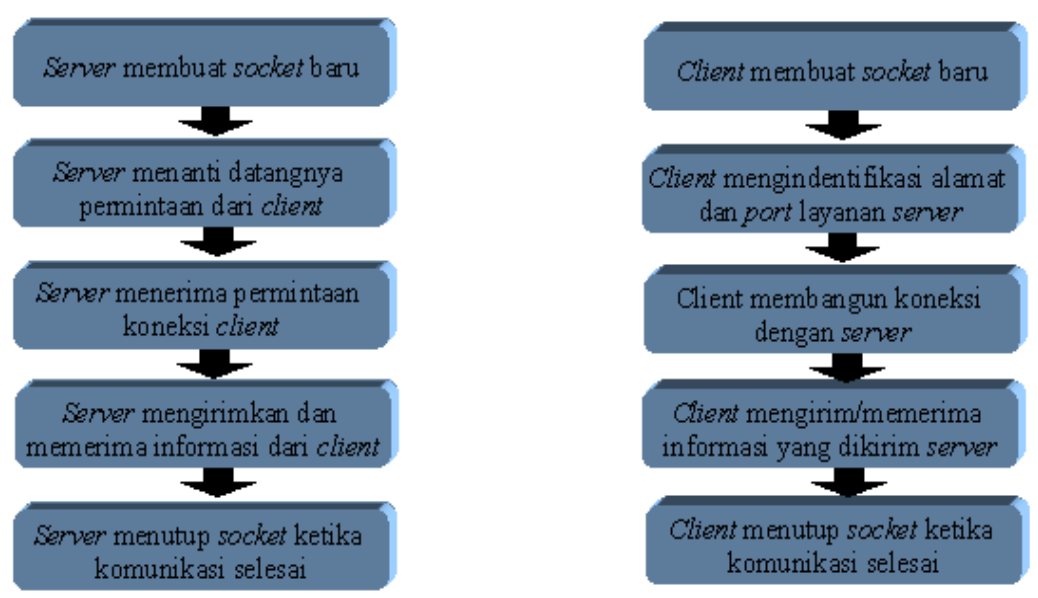

Gambar 5 Komunikasi client-server. 
Pada saat sebuah socket terbentuk, program harus menetapkan address domain dan tipe socket-nya. Dua buah dapat saling berkomunikasi satu dengan yang lainnya hanya jika tipe dan domain-nya sama. Ada dua domain address umum yang digunkan, yaitu:

a. Unix domain, adalah socket yang tidak dapat dijangkau dari internet sacara langsung, tetapi bersamaan dengan datangnya permintaan pada server.

b. Internet domain, adalah dua proses yang berjalan pada dua buah host dikomunikasikan internet. Alamat socket dari internet domain terdiri atas Internet address dari mesin host. Selain itu sebuah socket membutuhkan nomor port pada host-nya. Nomor port berupa 16 bit unsigned integers. Angka yang rendah disediakan dalam Unix untuk layanan standar. sebagai contoh nomor port untuk FTP server adalah 21. Hal ini penting bahwa layanan standar akan berada pada port yang sama pada semua komputer sehingga client akan mengetahui alamatnya. Ada port 65535 nomor port yang tersedia.

Untuk tipe socket ada 2 macam, stream socket dan datagram socket:

a. Stream socket adalah kominikasi continous stream dari karakter (menggunakan protokol TCP).

b. Datagram socket adalah pembacaan seluruh pesan dengan segera (mengggunakan protokol UDP) (Morgan Stern, 1998).

\section{Perancangan}

\section{Analisa kebutuhan sistem}

Dalam sistem yang akan dibuat ini terdapat beberapa permasalahan tentang bagaimana sistem yang dibuat bekerja serta kebutuhan software dan hardware untuk perancangan dan uji coba aplikasi.

\section{Analisa permasalahan}

Permasalahan tentang bagaimana aplikasi bekerja untuk memenuhi kebutuhan pengamanan yang diinginkan antara lain yaitu:

1 Bagaimana aplikasi melakukan capture packet data dari seluruh dari seluruh paket data yang masuk melalui proxy.

2 Bagaimana aplikasi melakukan filtering terhadap paket data yang dapat membahayakan jaringan lokal ataupun server.

3 Bagaimana aplikasi melaporkan gangguan keamanan kepada pengelola (administrator) secara real time.

4 Bagaimana aplikasi bisa bekerja sendiri tanpa harus terus diawasi administrator sehingga lebih efisien dalam pengawasan jaringan ataupun server.

Dari empat poin diatas dapat diketahui dasar permasalahan yang akan menjadi pokok dalam perancangan sistem. Dengan ini maka perancangan sistem nantinya diharuskan mensolusikan semua permasalan diatas, sebagai dasar perancangan dari empat poin diatas adalah packet capture, filtering, reporting, efficiency. Sistem pertahanan terhadap aktivitas gangguan saat ini umumnya dilakukan secara manual oleh administrator, hal ini mengakibatkan integritas sistem bergantung pada ketersediaan dan kecepatan administrator dalam merespon 
gangguan. Permasalahan ini yang menjadi titik berat perancangan sehingga integritas sistem tidak bergantung pada ketersediaan dan kecepatan administrator saja.

\section{Analisa sistem}

Sistem yang akan dibuat terdiri dari dua aplikasi yang bekerja sebagai satu kesatuan, yaitu aplikasi yang bekerja di-server dan aplikasi client, aplikasi di server bekerja melakukan capture packet data dan filtering terhadap paket data yang masuk dari luar, sedangkan aplikasi yang bekerja di-client bertugas menerima data hasil filtering dari aplikasi di-server lalu melaporkannya kepada administrator melalui SMS (short messages services). Aplikasi di-client juga mempunyai fungsi kontrol terhadap aplikasi yang berjalan di-server, hal ini dimaksudkan agar administrator tidak perlu melakukan kontak langsung dengan server untuk melakukan pengecekan. Kedua aplikasi tersebut mempunyai spesifikasi sebagai berikut:

a. Aplikasi Server

a. Packet capture, melakukan capture packet data yang masuk kedalam jaringan lokal.

b. Filtering, melakukan filter terhadap semua paket data yang masuk kedalam jaringan lokal berdasarkan port (port filter)

c. Trace route, melakukan pelacakan IP dan host name dari paket data yang membahayakan jaringan ataupun server.

d. Port setting, menyediakan konfigurasi port yang akan dibuka di-server, port yang telah dibuka ini untuk tujuan melakukan koneksi dengan aplikasi client sebagai penerima data yang akan dilaporkan nantinya.

b. Aplikasi Client

e. Send SMS, melakukan pengiriman SMS dengan tujuan pelaporan (report) hasil pengawasan yang dilakukan sistem kepada administrator.

f. Control capture, melakukan kendali terhadap aplikasi server untuk menjalankan dan memberhentikan aplikasi server dalam melakukan capture packet.

g. Port connect, melakukan koneksi ke aplikasi server melalui port yang telah dibuka diaplikasi server sehingga dapat mengontrol dan menerima data dari aplikasi server.

h. Viewer, Menampilkan data hasil capture dan hasil filter yang didapat dari hasil di-server, yang nantinya data-data yg ter-filter tersebut akan dilaporkan. Analisa kerja sistem notification dijelaskan pada gambar 6. 


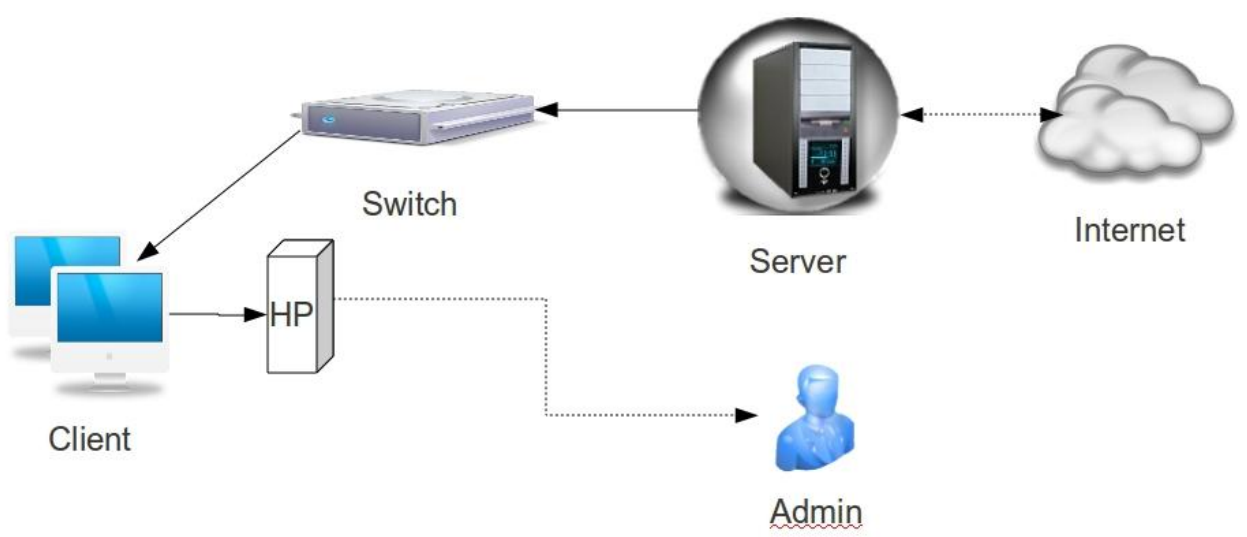

Gambar 6 Analisa kerja sistem notification.

\section{Analisa Filtering}

Dari hasil analisa diatas menitik beratkan pendeteksian berdasarkan filter data. Teknik filter yang digunakan adalah mendeteksi berdasarkan port yang digunakan. Dengan pendeteksian yang berdasar pada filtering paket data melalui penggunaan port service, maka kategori aktifitas illegal yang dapat di-filter penggunaan port service secara illegal. Kategori yang dimaksudkan adalah menggunakan sebuah port yang tidak diijinkan digunakan selain pengelola jaringan (administrator). Dalam filtering itu sendiri pengguna dapat menyesuaikan sesuai dengan kebutuhan sehingga tidak statis dalam filtering tapi lebih fleksibel berdasarkan kebutuhan pengguna sistem.

\section{Uji coba}

Sesuai dengan konfigurasi diatas maka akan disimulasikan percobaan untuk menjalankan aplikasi dan melakukan percobaan aktifitas yang dapat dideteksi oleh aplikasi. Dalam pengujian akan digunakan 2 komputer untuk mencoba melakukan aktifitas illegal dengan menggunakan 2 tools berbeda. Tools yang digunakan untuk percobaan yaitu dengan menggunakan Telnet dan SSH.

\section{Percobaan 1 (Telnet)}

Telnet adalah sebuah aplikasi yang digunakan untuk mengendalikan komputer ataupun mengakses komputer dari jauh, aplikasi ini biasanya digunakan untuk memudahkan administrator dalam mengakses suatu komputer tanpa harus ada didepan komputer tersebut. Namun dengan model akses seperti dapat memungkinkan siapa saja dapat mengakses komputer apabila berhasil mengetahui akun yang digunakan administrator untuk masuk, dengan begini aktifitas semacam ini dapat menjadi aktifitas yang illegal.

Skenario yang digunakan dalam percobaan pertama menggunakan telnet di komputer dengan IP 192.168.77.2, disini akan dicoba melakukan Telnet ke komputer server (program server berjalan), seperti pada gambar 7. Aplikasi yang berjalan di server akan mendeteksi ini dan menampilkannya serta mengirimkan ke aplikasi client untuk ditampilkan juga (gambar 8 dan 9). Data yang terdeteksi akan disimpan untuk dilakukannya proses trace route pada tahap selanjutnya 
(gambar 10). Setelah terdapat beberapa data yang masuk dan telah berhasil melakukan trace route maka semua data yang telah berhasil dikumpulkan akan dikirmkan ke aplikasi client melalui socket yang telah dibuat.

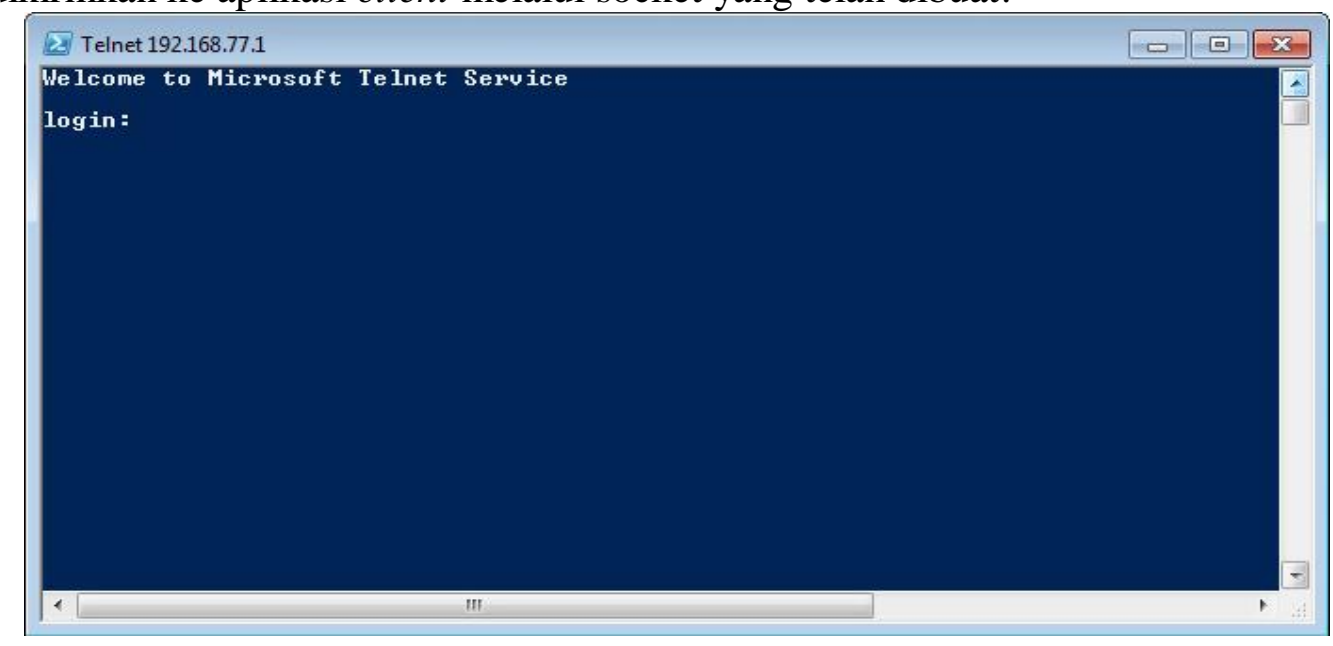

Gambar 7 Telnet ke komputer server.

\begin{tabular}{|c|c|c|c|c|c|c|c|}
\hline \multicolumn{8}{|c|}{ Filltered Data Capture } \\
\hline Time & Prot & Plen & Src IP: Port & Dest IP: Port & Service & DLen & Packet Data \\
\hline $18: 52: 01: 949$ & $\mathrm{TCP}$ & \multicolumn{4}{|c|}{$66 \quad 192160720940100$} & 0 & SYNACK \\
\hline $18: 52: 02: 447$ & TCP & $75<$ & $192.168 .77 .2: 49163$ & $192.168 .77 .1: 23$ & telnet & 21 & 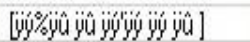 \\
\hline $18: 52: 02: 455$ & TCP & 62 & 152.100 .772400162 & 192168721.22 & dellot & 8 & 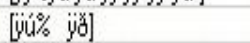 \\
\hline $18: 52: 02: 462$ & TCP & 89 & $192.168 .77 .2: 49163$ & $192.168 .77 .1: 23$ & telnet & 35 & [ijú yơzyú SFUTLNTVE... \\
\hline $18: 52: 04: 118$ & TCP & 92 & $192.168 .77 .2: 49163$ & $192.168 .77 .1: 23$ & telnet & 38 & Welcome to Microsoft T... \\
\hline $18: 52: 04: 133$ & TCP & 63 & $192.168 .77 .2: 49163$ & $192.168 .77 .1: 23$ & telnet & 9 & [ login:] \\
\hline $18: 52: 04: 349$ & TCP & 54 & $192.168 .77 .2: 49163$ & $192.168 .77 .1: 23$ & telnet & 0 & $\mathrm{ACK}$ \\
\hline & & & & & & & \\
\hline & & & & & & & \\
\hline & & & & & & & \\
\hline
\end{tabular}

Gambar 8 Server mendeteksi aktifitas Telnet dari IP 192.168.77.2. 


\begin{tabular}{|c|c|c|c|c|c|c|c|}
\hline \multicolumn{8}{|c|}{ Packet Capture } \\
\hline Time & Prot & PLen & Sic IP: Port & Dest IP : Port & Service & DLen & Packet Data \\
\hline 18:52:01:371 & TCP & 54 & $192.168 .77 .2: 49160$ & 192.168.77.1:2846 & $\langle 2846\rangle$ & & \\
\hline $18: 52: 01: 371$ & TCP & 430 & 192.168.77.1:2846 & $192.168 .77 .2: 49160$ & $\langle 49160\rangle$ & 376 & [ 18:52:01:152 TCP $540192.168 .77 \ldots$. \\
\hline 18:52:01:605 & TCP & 54 & $192.168 .77 .2: 49160$ & $192.168 .77 .1: 2846$ & $\langle 2846\rangle$ & 0 & \\
\hline 18:52:01:608 & TCP & 430 & $192.168 .77 .1: 2846$ & 192.168.77.2:49160 & $\langle 49160\rangle$ & 376 & [ 18:52:01:371 TCP 540 192.168.77... \\
\hline 18:52:01:641 & UDP & 217 & $192.168 .77 .1: 138$ & 192.168.77.255:138 & netbios-data & 175 & I èAM Ii EMEFEOEPFGEPCACA... \\
\hline 18:52:01:642 & UDP & 217 & 192.168.77.1:138 & 192.168.77.255:138 & netbios-data & 175 & I èAM I। EMEFEOEPFGEPCACA... \\
\hline 18:52:01:823 & TCP & 54 & 192.168.77.2:49160 & 192.168.77.1:2846 & $\langle 2846\rangle\rangle$ & & \\
\hline 18:52:01:824 & TCP & 806 & & & $-19160\rangle$ & 752 & [ 18:52:01:605 TCP $540192.168 .77 \ldots$. \\
\hline 18:52:01:948 & TCP & & $192.168 .77 .2: 49163$ & 192.168.77.1:23 & telnet - & 0 & \\
\hline 18:52:01:949 & TCP & & & & & 0 & SYNACK \\
\hline 18:52:02:440 & TCP & 54 & 192.168.77.2:49163 & $192.168 .77 .1: 23$ & telnet & 0 & ACK \\
\hline 18:52:02:444 & TCP & 54 & 192.168.77.2:49160 & 192.168.77.1:2846 & $\langle 2846\rangle$ & 0 & ACK \\
\hline 18:52:02:445 & TCP & 618 & 192.168.77.1:2846 & 192.168.77.2:49160 & $\langle 49160\rangle$ & 564 & [ 18:52:01:823 TCP 547 192.168.77... \\
\hline 18:52:02:445 & UDP & 85 & 192.168.77.1:49803 & $224.0 .0 .252: 5355$ & $\langle 5355\rangle$ & 43 & [ [ê $\quad 277168192$ in-addr arpa ] \\
\hline 18:52:02:446 & UDP & 85 & 192.168.77.1:49803 & 224.0.0.252:5355 & $\langle 5355\rangle$ & 43 & 277168192 in-addr arpa \\
\hline 18:52:02:447 & UDP & 129 & 192.168.77.2:5355 & 192.168.77.1:49803 & $\langle 49803\rangle$ & 87 & [ [ \\
\hline 18:52:02:447 & TCP & 75 & 192.168.77.1:23 & 192.168.77.2:49163 & telnet & 21 & 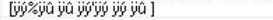 \\
\hline 18:52:02:454 & TCP & 57 & 192.168.77.2:49163 & 192.168.77.1:23 & telnet & 3 & [iü\%] \\
\hline 18:52:02:455 & TCP & 62 & 192.168.77.1:23 & 8.77.2:49163 & telnet & 8 & 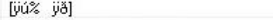 \\
\hline 18:52:02:462 & TCP & 81 & 192.168.77.2:49163 & 1.77.1:23 & telnet & 27 & 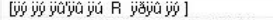 \\
\hline 18:52:02:462 & TCP & 89 & 1.77.1:23 & 77.2:49163 & telnet & 35 & [jứ' 'yżjü' SFUTLNTVER SFUTLNT.... \\
\hline 18:52:02:466 & TCP & 54 & .77.2:49160 & 77.1:2846 & $\langle 2846\rangle$ & 0 & ACK \\
\hline 18:52:02:466 & TCP & & 77.2:49 & 7.1:23 & telnet & 0 & \\
\hline 18:52:02:466 & TCP & 242 & $.1: 2$ & 7.2:49160 & $\langle 49160\rangle$ & 188 & [ 18:52:01:949 TCP 666 192.168.77... \\
\hline 18:52:02:467 & TCP & 151 & 192 & & $<49$ & 146 & [ 18:52:02:440 TCP 546 192.168.77 $\ldots$ \\
\hline 18:52:02:467 & TCP & 98 & 19 & 19 & $<49$ & 44 & [2 in-addr arpa $\quad$ goien $\gamma A C K e ̀$ A \\
\hline 18:52:02:467 & TCP & 54 & 19 & 19 & & 0 & \\
\hline 18:52:02:467 & TCP & 430 & .1:28 128 & 160 & $<491$ & 376 & [ 18:52:02:455 TCP 629 192.168.77\%. \\
\hline 18:52:02:468 & TCP & 151 & 192.16 & 192. & $\langle 49160\rangle$ & 146 & [ 18:52:02:462 TCP 899 192.168.77 $\ldots$ \\
\hline 18:52:02:468 & TCP & 98 & 192.168.77.1:2846 & 192.168.77.2:49160 & $\langle 49160\rangle$ & 44 & 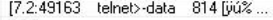 \\
\hline 18:52:02:478 & TCP & 54 & 192.168.77.2:49160 & 192.168.77.1:2846 & $\langle 2846\rangle$ & 0 & ACK \\
\hline $18: 52 \cdot 02 \cdot 479$ & $T \Gamma P P$ & 4.30 & $1.971687771 \cdot 2846$ & $1.9>168777\urcorner-4916 n$ & $\langle 4.916 \cap\rangle$ & .376 & 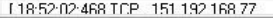 \\
\hline
\end{tabular}

Gambar 9 Client menampilkan kiriman data dari server.

Trace Route Filltered Address
\begin{tabular}{|l|l|l|l||}
\hline Hop & IP Address & Info Time & Host Name \\
\hline 1 & 192.168 .77 .2 & Reached in : 0 ms & gojen \\
\hline & & & \\
\hline & & & \\
\hline & & & \\
\hline
\end{tabular}

Gambar 10 Hasil Trace route ke IP 192.168.77.2.

\section{Percobaan 2 (SSH)}

SSH (Secure Shell Hosting) adalah aplikasi remote computer, sama halnya dengan telnet namun SSH tidak mengirimkan data dalam bentuk plain text yang mudah dibaca oleh orang. SSH melakukan pengiriman data remoting dalam keadaan telah terenkripsi sehingga membuat SSH lebih aman dibandingkan telnet. Tetapi dengan keamanan yang dimiliki SSH juga akan menjadi masalah apabila ada akses ke komputer yang tidak di inginkan menggunakan SSH. Dengan begitu penggunaannya akan sangat menguntungkan tetapi juga sebaliknya apabila digunakan untuk akses illegal.

Percobaan ke-2 dengan skenario yang sama tetapi menggunakan komputer berbeda dengan IP 192.168.77.3. Dipercobaan ke-2 tools yang digunakan adalah SSH. Sama halnya dengan percobaan pertama, SSH akan digunakan untuk mencoba melakukan remoting ke komputer server. Percobaan ke-2 seperti pada 
gambar 11, hasil dari percobaan ini seperti pada gambar 12. Sama seperti halnya tahap terakhir adalah program melakukan trace route terhadap hasil yang terdeteksi pada proses filtering sebelumnya.

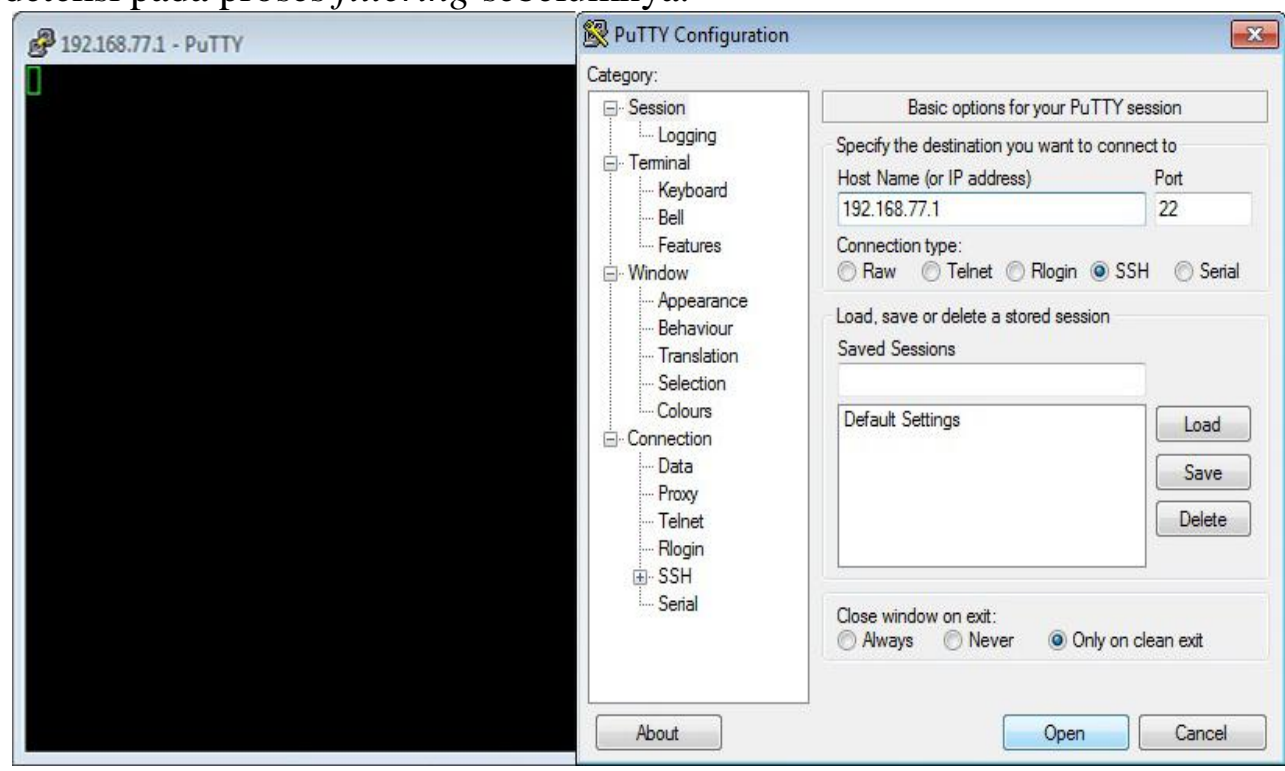

Gambar 11 SSH ke komputer server.

\begin{tabular}{|c|c|c|c|c|c|c|c|}
\hline \multicolumn{8}{|c|}{ Filltered Data Capture } \\
\hline Time & Prot & Plen & Src IP: Port & Dest IP: Port & Service & DLen & Packet Data \\
\hline 18:52:01:949 & TCP & 66 & 192.168 .77 .2 .49163 & 192.168.77.1:23 & telnet & 0 & SYNACK \\
\hline $18: 52: 02: 447$ & TCP & 75 & 192.168 .77 .2 .49163 & $192.168 .77 .1: 23$ & telnet & 21 & 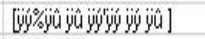 \\
\hline $18: 52: 02: 455$ & TCP & 62 & 192.168 .77 .2 .49163 & $192.168 .77 .1: 23$ & telnet & 8 & 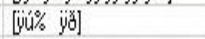 \\
\hline $18: 52: 02: 462$ & TCP & 89 & $192.168 .77 .2: 49163$ & $192.168 .77 .1: 23$ & telnet & 35 & [ứ jớoún SFUTLNTVE.. \\
\hline $18: 52: 04: 118$ & TCP & 92 & 192.168 .77 .2 .49163 & $192.168 .77 .1: 23$ & telnet & 38 & Welcome to Microsoft T... \\
\hline $18: 52: 04: 133$ & TCP & 63 & 192.168 .77 .2 .49163 & 192.168.77.1:23 & telnet & 9 & [ login:] \\
\hline $18: 52: 04: 349$ & TCP & 54 & 100 - & TS2.168677.1.20 & & 0 & ACK \\
\hline $19: 06: 25: 235$ & TCP & & 192.168 .77 .3 .49170 & 192.168.77.1:22 & ssh & 0 & RST ACK \\
\hline $19: 06: 25: 768$ & TCP & 54 & & 102150771.20 & & 0 & RST ACK \\
\hline $19: 06: 26: 295$ & TCP & 54 & 192.168 .77 .3 .49170 & $192.168 .77 .1: 22$ & ssh & 0 & RST ACK \\
\hline
\end{tabular}

Gambar 12 Server mendeteksi aktifitas SSH dari IP 192.168.77.3.

\section{Notification}

Hasil dari semua uji coba diatas akan memenuhi kuota untuk melakukan pemberitahuan (Notification) kepada administrator tentang aktifitas yang terdeteksi pada server melalui sms. Aktifitas yang dilaporkan ke administrator adalah aktifitas pertama komputer tersebut ke komputer server (Gambar 13). Dari aktifitas tersebut akan dilaporkan melalui SMS dengan format : waktu, IP, nama komputer, services, port . 


\begin{tabular}{|c|c|c|c|c|c|c|c|}
\hline \multicolumn{8}{|c|}{ Filltered Data Capture } \\
\hline Time & Prot & Plen & \multicolumn{3}{|c|}{ 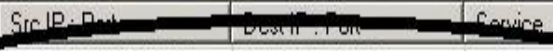 } & OLen & Packet Data \\
\hline $18: 52: 01: 949$ & TCP & $(10$ & $192.168 .77 .2: 49163$ & 192.168.77.1.23 & telnet & 0 & SYNACK \\
\hline $18: 52: 02: 447$ & TCP & & -10216972249163 & 192.168.77.1.23 & falpoin & 21 & 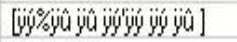 \\
\hline $18: 52: 02: 455$ & TCP & 62 & 192.168 .77 .2 .49763 & $192.168 .7 / 1: 23$ & telnet & 8 & [ijư jüz] \\
\hline $18: 52: 02: 462$ & TCP & 89 & 192.168 .77 .2 .49163 & $192.168 .77 .1: 23$ & telnet & 35 & [jứ jözju'́ SFUTLNTVE... \\
\hline 18:52:04:118 & TCP & 92 & 192.168 .77 .2 .49163 & $192.168 .77 .1: 23$ & telnet & 38 & [Welcome to Microsoft T. \\
\hline $18: 52: 04: 133$ & TCP & 63 & 192.168 .77 .2 .49163 & 192.168.77.1:23 & telnet & 9 & [ login:] \\
\hline $18: 52: 04: 349$ & TCP & 54. & 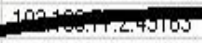 & 752.168 .77 .120 & & 0 & $\mathrm{ACK}$ \\
\hline $19: 06: 25: 235$ & TCP & (14: & 192.168 .77 .3 .49170 & 192.168.77.1:22 & $\operatorname{ssh}$ & 0 & RST ACK \\
\hline $19: 06: 25: 768$ & $\mathrm{TCP}$ & 54 & & 192160771.22 & & 0 & RST ACK \\
\hline $19: 06: 26: 295$ & TCP & 54 & 192.168.77.3.49170 & $192.168 .77 .1: 22$ & ssh & 0 & RST ACK \\
\hline
\end{tabular}

Gambar 13 Aktifitas pertama komputer penyerang.

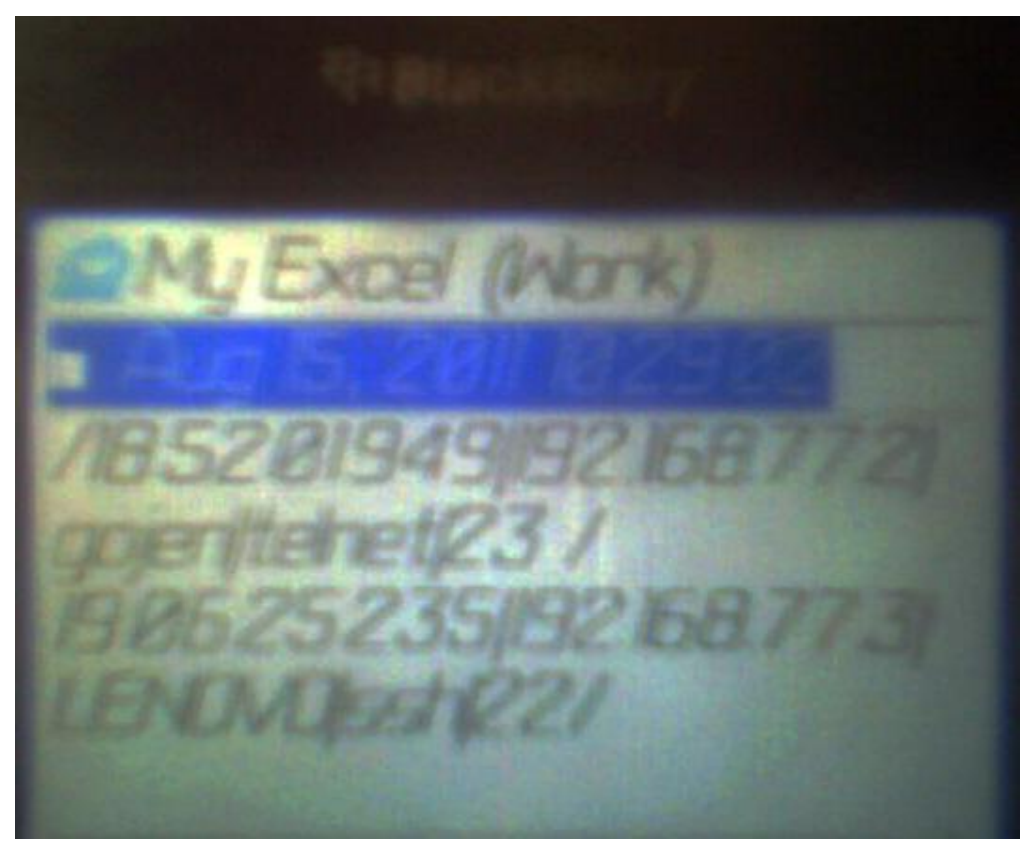

Gambar 14 SMS yang diterima oleh administrator.

\section{Pengujian Gangguan dari dalam dan luar}

Pada tahap percobaan seperti pada sub-bab sebelumnya, dilakukan juga percobaan tidak hanya dari jaringan dalam (jaringan lokal) tetapi juga dari jaringan luar (Internet). Percobaan yang dilakukan untuk jaringan luar dan dalam, dilakukan dengan cara melakukan filter terhadap semua opsi yang ada pada konfigurasi filtering port. Percobaan percobaan ini dimaksudkan untuk memastikan bahwa aplikasi dapat melakukan capture terhadap semua aliran data yang keluar dan masuk jaringan yang diuji. Hasil dari percobaan ini dapat dilihat pada tabel pengujian gangguan dari dalam dan luar.

Tabel 1 Tabel pengujian gangguan dari dalam dan luar

\begin{tabular}{|c|c|c|c|}
\hline No. & Gangguan / Alamat IP & Jenis Sambungan & Ter-Capture \\
\hline 1. & Telnet / 192.168.77.2 & Sekelas (Lokal) & Ya \\
\hline
\end{tabular}




\begin{tabular}{|l|c|c|c|}
\hline 2. & SSH / 192.168.77.3 & Sekelas (Lokal) & Ya \\
3. & HTTP / 74.125.235.50 & Tidak Sekelas (Internet) & Ya \\
4. & POP3 / 202.182.170.10 & Tidak Sekelas (Internet) & Ya \\
\hline
\end{tabular}

\section{Pengujian pada operator selular}

Pengujian pada operator selular yang dimaksudkan adalah pengujian terhadap biaya dan kecepatan dalam mengirimkan pesan. Pengujian pada operator selular bertujuan agar aplikasi dapat memenuhi kebutuhan sistem yang efisien dan real time. Pengujian dilakukan dengan menggunakan beberapa operator berbeda. Hasil dari pengujian ini dapat dilihat pada tabel 2 tabel pengujian pada operator selular.

Tabel 2 Tabel pengujian pada operator selular

\begin{tabular}{|c|c|c|c|}
\hline No. & Operator Selular & Biaya $(\mathrm{Rp})$ & Waktu (detik) \\
\hline 1. & Telkomsel & $150 / \mathrm{sms}$ & 4 \\
2. & Indosat & $150 / \mathrm{sms}$ & 6 \\
3. & Excelindo & $150 / \mathrm{sms}$ & 5 \\
\hline
\end{tabular}

\section{Analisa sistem}

Hasil dari semua percobaan dapat di analisa dari implementasi dan simulasi percobaan adalah tentang proses mekanisme kerja dari sistem secara keseluruhan. Secara keseluruhan hasil analisa terdiri dari konsep dasar yang dibangun untuk menjadi sebuah sistem sesuai dengan yang telah dibahas dan analisa dari hasil percobaan adalah sebagai berikut :

a. Filtering (port filter) yang dikerjakan program dapat disesuaikan dengan keinginan pengguna, dengan ini sistem filtering data dapat lebih fleksibel.

b. Notification akan dikirimkan setelah adanya beberapa aktifitas gangguan dari beberapa IP berbeda. Proses ini membuat pengiriman notification lebih efisien.

c. Dari point $b$, dapat dianalisa bahwa setiap IP (Komputer penyerang) dapat melakukan beberapa aktifitas illegal sekaligus yang ter-filter sehingga yang dilaporkan tidak berdasarkan jumlah aktifitas gangguan tetapi berdasarkan IP.

d. Proses dari trace route hanya dapat mengambil nama komputer (Host Name) dari komputer penyerang. Semua proses hop to hop dari trace dapat terlihat tetapi hanya ujung dari proses yang digunakan untuk notification.

e. Proses filtering dapat menangkap semua aliran paket data dari dalam (lokal area) maupun dari luar (internet) yang melewati server.

\section{Kesimpulan}

a. Sistem yang telah dibangun administrator dapat mengawasi penggunaan port ataupun server dengan lebih efisien dan real time sehingga pengawasan administrator tidak lagi harus tergantung pada keberadaan.

b. Administrator dapat mengetahui penggunaan port secara illegal (percobaan penyerangan / gangguan) melalui teknik filter port service pada lalulintas data yang keluar masuk, baik dari jaringan internal maupun eksternal.

c. Kehandalan aplikasi server dalam melakukan capture terhadap seluruh paket yang melintas membuat proses filtering dapat lebih akurat sehingga setiap aktifitas dapat terpantau dengan baik. 
d. Kecepatan pengiriman notification secara real time tergantung kepada operator selular yang digunakan untuk mengirimkan SMS.

\section{Saran}

1. Pada penelitian selanjutnya menambahkan informasi dalam notification tentang dampak (impact) dari gangguan serta status terakhir dari server ataupun jaringan yang dikelola.

2. Memperluas kemampuan filter agar opsi filtering yang lebih banyak dan tidak hanya melakukan filter pada port service sehingga kemungkinan pendeteksiannya lebih banyak.

3. Penambahan fitur Whois yang akan ditambahkan juga sebagai salah satu basis informasi pada notification sehingga lebih memudahkan administrator dalam menindak lanjuti informasi yang didapatkan.

\section{DAFTAR PUSTAKA}

Budi Sutedjo Dharma Oetomo, S.Kom.,MM, Eddy Hartono, S.Kom,.MT, Ester Wibowo, BA.,MM.,MT, Samuel Prakoso, S.Kom, 2006, Konsep dan Aplikasi Pemprograman Client Server dan Sistem Terdistribusi, Andi Offset (Andi), Yogyakarta.

Dony Ariyus., M.Kom, 2007, Intrusion Detection System, Andi Offset (Andi), Yogyakarta.

Edhy Sutanta, 2005, Komunikasi Data dan Jaringan Komputer, Graha Ilmu, Yogyakarta.

Jhonathan Lukas, 2006, Jaringan Komputer, Graha Ilmu, Yogyakarta.

Melwin Syafrizal, 2005, Pengantar Jaringan Komputer, Andi Offset (Andi), Yogyakarta.

William Stallings, 2007, Komunikasi dan jaringan Nirkabel, jilid 1, Edisi Kedua, Erlangga, jakarta. 